\title{
Entre libros y fusiles: la formación ideológica de la juventud garridista y los “Camisas Rojas” en Tabasco, 1922-1935
}

\author{
Between Books and Rifles: the Ideological \\ Formation of Garridista Youth and the \\ "Red Shirts" in Tabasco, 1922-1935
}

\author{
Ivonne Meza Huacuja \\ (D) 0000-0002-7311-8857 \\ Instituto de Investigaciones Dr. José María Luis Mora, México \\ ivy.meza@gmail.com
}

Resumen: Para algunos especialistas, el proyecto político-social del gobierno de Tomás Garrido Canabal en Tabasco sobresalió por su autonomía, radicalidad y popularidad respecto al desarrollado en otras entidades del país. En el presente artículo se analizan los discursos construidos en algunos periódicos tabasqueños sobre los jóvenes durante el régimen garridista y su papel como participantes en el cumplimiento de algunos preceptos revolucionarios. También se examina el impacto de la educación racionalista y del Instituto Juárez en las identidades juveniles y en la conformación de la ideología del Bloque de Jóvenes Revolucionarios, organización fundamental para las políticas garridistas y la sobrevivencia del régimen. La investigación demuestra el impacto de la educación formal e informal en la construcción de distintas maneras de comprender la realidad circundante, de las identidades mismas y la función de los distintos sectores en su entorno.

cómo citar: Meza Huacuja, I. (2019). Entre libros y fusiles. La formación ideológica de la juventud garridista y los "Camisas Rojas" en Tabasco, 1922-1935. Secuencia (105), e1565. DoI: https://doi. org/10.18234/secuencia.v0i105.1565

(c) (i) () Esta obra está protegida bajo una Licencia Creative Commons Atribución-NoComercial 4.0 Internacional. 
Palabras clave: garridismo; Bloque de Jóvenes Revolucionarios; educación racionalista; juventudes radicales; representaciones.

Abstract: For a number of specialists, the political-social project of the government of Tomás Garrido Canabal in Tabasco stood out because of its autonomy, radicalism and popularity in regard to those developed in other parts of the country. This article analyzes the discourses constructed in various newspapers of Tabasco on young people during the Garrido regime and their role as participants in fulfilling certain revolutionary precepts. It also examines the impact of the rationalist education and the Juárez Institute on youth identity and the creation of the ideology of the Revolutionary Youth Block, a key organization for Garrido's policies and the survival of the regime. The research demonstrates the effect of formal and informal education on the formation of various ways of understanding the surrounding reality, identity and the function of the various sectors.

Key words: garridism; Revolutionary Youth Block; rationalist education; radical youth; representations.

Fecha de recepción: 7 de noviembre de 2017 Fecha de aceptación: 25 de octubre de 2018

$E^{1}$ estallido de la revolución mexicana constituyó, sin lugar a duda, un momento de corte y renovación de las funciones y significaciones de ciertos sectores y grupos sociales respecto al nuevo proyecto nacional y al resto de la sociedad. Así, la nueva retórica revolucionaria a la que se integró a campesinos, obreros y mujeres estuvo acompañada por el interés en la formación de niños y jóvenes. De modo que el control sobre la educación formal e informal de estos dos grupos representó la materialización y sobrevivencia de los preceptos revolucionarios, la construcción de un sentimiento de unidad nacional y el intento de monopolizar, por parte del gobierno, la construcción 
del "hombre nuevo", siendo uno de los objetivos prioritarios de las nuevas administraciones. ${ }^{1}$

En ese sentido, a partir de la llegada de Álvaro Obregón a la presidencia del país, paulatinamente se hicieron renovados esfuerzos por extender la entonces llamada federalización -ahora entendida como centralización- de la educación a sectores más amplios del país y por homogeneizar el contenido de las enseñanzas, en particular con la creación de la Secretaría de Educación Pública (SEP) por José Vasconcelos en 1921. La escuela se convirtió en el máximo difusor de algunos principios ideológicos del nuevo régimen, así como de creencias, prácticas y representaciones sociales.

Mediante programas de estudio, ceremonias, concursos y actividades extracurriculares se buscó que los estudiantes asimilaran las nuevas nociones de ciudadanía. Asimismo, por medio de la difusión del nacionalismo cultural mexicano y del cultivo de hábitos propios de los países civilizados (la higiene, la solidaridad, el ahorro y la templanza) se promovió un sentimiento de unidad nacional y pertenencia al país.

La formación de niños y jóvenes también fue objeto de disputa por parte de las iglesias de distintos credos, de partidos políticos, e incluso entre facciones del gobierno con proyectos político-sociales que podían discrepar de los que pregonaba el gobierno central, como fue el caso de Tomás Garrido Canabal en Tabasco (1922-1934). En este tenor -aunque circunscrito por particularidades políticas y geográficas-, es que surge el interés por esta investigación, que estudia la formación ideológica de la juventud tabasqueña, específicamente de los líderes del Bloque de Jóvenes Revolucionarios (BJR) o "Camisas Rojas" -todos ellos educados en el renombrado Instituto Juárez-, cuya organización originada en Tabasco puede rastrearse desde 1931.

Dicha organización emanó de las Ligas de Resistencia supeditadas al Partido Socialista Radical de Tabasco, a cuyo frente se encontraba el gobernador Tomás Garrido Canabal y, de acuerdo con algunos investigadores, fue el

${ }^{1}$ De acuerdo con Beatriz Urías Horcasitas (2007) el origen de la idea de un "hombre nuevo" surgió por primera vez en Europa en el siglo xvi como parte de las utopías que acompañaron el periodo de descubrimientos y colonización de América. Progresivamente, el contexto político y social contribuyó a la transformación de las expectativas y significados de dicho concepto. La idea de "hombre nuevo" que aquí compete conjugó algunas versiones del siglo XIX que pugnaban por la regeneración moral y cívica del individuo desde una perspectiva secularizante con las de la primera mitad del siglo xx como resultado de la incorporación de la educación racionalista difusora de la libertad y el espíritu crítico entre los educandos. 
arma social más eficiente para el reforzamiento de la política desfanatizadora y antialcohólica de su régimen (Kirshner, 1976, p. 55; Torres, 2001, p. 50). Posteriormente, en 1934, cuando Garrido fue invitado por Lázaro Cárdenas para ocupar la Secretaría de Agricultura y Fomento con sede en la ciudad de México, algunos líderes del BJR en Tabasco organizaron una rama en la capital del país, que para entonces se convirtió en la base de operaciones con la que se buscó la expansión del proyecto garridista a todo el país.

Si bien el BJR tuvo presencia en otras entidades de la república como Michoacán, Durango, Veracruz, Oaxaca y San Luis Potosí, me centraré en la formación de los sectores que lo encabezaban: estudiantes de nivel secundaria, preparatoria y profesional del Instituto Juárez de Tabasco. Para ello revisé los discursos y expectativas sobre la juventud de maestros, políticos y estudiantes tabasqueños, todos ellos rescatados del periódico oficialista Redención y de La Voz del Estudiante, órgano de los estudiantes del Instituto Juárez, así como de algunos documentos y oficios del fondo Tomás Garrido Canabal que alberga el Archivo General de la Nación.

Mediante el presente artículo repasaré brevemente algunas premisas fundamentales de la educación racionalista, el sistema educativo oficial del régimen y ciertas características de la secundaria y preparatoria del Instituto Juárez de Tabasco fundamentales para la formación ideológica e identitaria del BJR. No obstante, mi objetivo principal será el análisis de los discursos construidos desde arriba -es decir, en términos políticos, los de los sectores dominantes- sobre la juventud y el gremio estudiantil (ambos términos profundamente entrelazados); examinar el contenido de los artículos y columnas que escribían los jóvenes en los periódicos locales, para entender los modos de negociación y asimilación de las representaciones generadas por las autoridades y rescatar las formas y el papel de la juventud estudiosa en el proyecto garridista y revolucionario.

Mi premisa central consiste en que los elementos mencionados dan cuenta de cómo los discursos y políticas formativas inciden en la difusión de ideologías, es decir, en cómo las representaciones sociales intervienen en la generación de actitudes y prácticas específicas entre los individuos o grupos en los que recaen, ya sea a modo de asimilación, negociación o resistencia.

El ejemplo que expondré a continuación refuerza algunas investigaciones en boga desde la década de 1980 que cuestionaban la existencia de un gobierno federal hegemónico con dominio absoluto sobre todos los ámbitos de la vida política, económica y social de la población del país durante el periodo 
posrevolucionario. Al rescatar el caso de la formación de los líderes del BJR en Tabasco pretendo ilustrar el proceso de reforzamiento del poder estatal y federal por parte de un sector específico a través de su educación y el establecimiento de una organización juvenil progubernamental.

\section{EDUCACIÓN, JUVENTUD Y ESTADO: UNA VISIÓN PANORÁMICA}

A finales del siglo XVIII los nacientes Estados-nación tomaron el control de los centros educativos en occidente, lo que significó el desplazamiento de los gremios y de los padres de familia de sus funciones como formadores de las nuevas generaciones. La misión de las escuelas modernas fue la modelación del individuo, formación intelectual, moral, cívica y física.

Con el paso de los años las escuelas se consolidaron como espacios en los que se impulsó y difundió la ideología de un sector social particular o de un grupo en el poder. Así, en su función como instructora de amplios sectores poblacionales, la escuela tuvo un papel fundamental en el control, difusión y codificación del comportamiento social y de las relaciones entre grupos (por género, clase social, grupo de edad y credo religioso). Como parte de ella, tanto el currículum escolar como los maestros (entendidos como difusores de los saberes y del corpus de ideas presentes en el currículum -o incluso como opositores al mismo-) han desempeñado un papel fundamental en la promoción de ciertos objetivos políticos, económicos y sociales propios o construidos por sectores hegemónicos (Apple, 2008).

Para los fines del presente trabajo, además de los dos agentes mencionados, vale la pena destacar el papel de los jóvenes durante dicho proceso educativo. Esto en cuanto a la recepción de los contenidos ideológicos de su educación; transformación y aceptación de estos y, sobre todo, la estrecha relación entre dicho aprendizaje y la percepción sobre su función como grupo social -particularmente identificados como un grupo etario respecto a su país y la sociedad que los rodea.

Ahora bien, antes de proseguir, es imprescindible resaltar un segundo elemento para lograr entender el problema que se desarrolla en las siguientes páginas: la visibilidad que tuvieron los jóvenes como grupo de edad en las sociedades occidentales modernas, particularmente a partir del siglo XIX (Souto, 2007, p. 172). De acuerdo con algunos especialistas en historia de la 
juventud, dicha condición fue producto de la gran gama de transformaciones que produjo la revolución industrial y de la consolidación de los Estados nacionales como formas de gobierno predominante en occidente (Comacchio, 2006; Gillis, 1974; Kett, 1977; Souto, 2007).2

Así pues, de ser parte de una imagen predominantemente decadentista a finales del siglo xIx y principios del $\mathrm{xx}$, los jóvenes pasaron poco a poco a ser integrados como agentes de transformación en algunos proyectos políticos de corte nacionalista. Tal y como afirma Sandra Souto, la primera guerra mundial contribuyó a una nueva actitud de los jóvenes respecto a su identidad y capacidad de agencia, que consistió en su desarrollo como grupo independiente y en la formación de asociaciones netamente juveniles. Para algunos sectores del mundo adulto, los jóvenes representaron la fuerza que permitiría la renovación y regeneración de los Estados-nación golpeados por la guerra (Souto, 2013, pp. 21-23).

Algunos casos que ejemplifican esta nueva forma de socialización intergrupal son la expedición en 1922 de la Ley de Bienestar de la Juventud de la República de Weimar en Alemania (Harvey, 1993) y la constitución en 1923 de la Opera Nazionale Balilla (onB) en Italia, rama juvenil del Partido Nacional Fascista también conocida como "Camisas Negras". El BJR guardó gran semejanza en particular con esta última al retomar como preceptos algunos postulados de la escuela racionalista tabasqueña (particularmente la utilización de la bandera del racionalismo para justificar sus posturas y acciones anticlericales), pues el establecimiento de las ONB formó parte de un programa de reforma escolar impulsado por el entonces ministro de Educación Giovanni Gentile (consultado por algunos pedagogos mexicanos como Ezequiel A. Chávez), quien buscó la formación militar y física de niños y "adolescentes" varones de entre 6 y 18 años de edad (Cox, 1935; Fincardi, 2007, p. 54).

2 También pueden citarse los avances médicos, el aumento demográfico, el mejoramiento de las vías de comunicación, el desarrollo de la industria, el crecimiento de las ciudades, los cambios en la estructura y dinámica familiar, así como los esfuerzos por expandir la educación a sectores más amplios de la población. Todos estos elementos contribuyeron a la ampliación de la edad de dependencia de los hijos respecto a sus padres, a la presencia en las calles de niños y jóvenes (algunos de ellos agrupados en pandillas) y a la preocupación de ciertos sectores sociales (políticos y religiosos) por controlar el tiempo libre de los jóvenes y prepararlos para que no sucumbieran en los vicios y tentaciones de las grandes ciudades (el alcoholismo, el tabaquismo, la prostitución y las apuestas). 


\section{GÉNESIS Y CONSOLIDACIÓN DEL GARRIDISMO TABASQUEÑO}

Recientes reinterpretaciones sobre la hegemonía del Estado mexicano posrevolucionario señalan que esta fue construida e impugnada regionalmente, por medio de múltiples arreglos y negociaciones locales y culturales replicadas tanto en el ámbito de las interacciones cotidianas como en el juego de las altas esferas de la política nacional (Rubin, 2003, p. 128). Así, la coexistencia de cacicazgos con las nuevas dirigencias regionales y nacional y la pervivencia de la organización comunitaria y de prácticas culturales, contribuyeron al fortalecimiento de las administraciones locales y de la imagen de un gobierno central todopoderoso mediante múltiples alianzas entre los gobiernos y actores de los distintos niveles gubernamentales y sociales (Rubin, 2003, p. 128; Vries, 2002).

En ese sentido, algunos autores como Pieter de Vries (2002) y Carlos Martínez Assad (1988), entre otros, han resaltado el papel sobresaliente de los caciques regionales como intermediarios entre políticos de mayor rango y la población en general; la formación de relaciones clientelares a cambio del reclutamiento político, el financiamiento de campañas electorales y la paz social.

Prácticamente todas las investigaciones sobre el régimen de Tomás Garrido Canabal, quien gobernó Tabasco sin interrupción de 1919 a 1934, coinciden en subrayar el impacto de las condiciones geográficas del estado en el desarrollo histórico de la entidad (Canudas, 1989; Kirshner, 1976; Martínez, 1984; Tostado, 1991). De este modo, la afluencia en su territorio de numerosos ríos, lagos, lagunas y pantanos, además de regiones selváticas, manglares y sabanas tropicales, dificultó la evangelización católica durante el virreinato y el control del gobierno federal durante los siglos XIX y principios del xx.

A su vez, estas circunstancias facilitaron el desarrollo del proyecto revolucionario radical garridista, que retomó la experiencia de algunos predecesores como el anticlericalismo del general Francisco J. Múgica (1915-1916) y del presidente Plutarco Elías Calles (1924-1928) y la de los gobiernos socialistas y progresistas de Salvador Alvarado y Felipe Carillo Puerto en Yucatán (Giuseppe, 2011).

De acuerdo con el historiador italiano Massimo de Giuseppe (2011, p. 649), en el plano internacional Garrido se interesó en el nacionalismo impulsado en la Italia fascista. Otros investigadores, como Carlos Martínez Assad, resaltan el parecido de las Ligas de Resistencia del Partido Socialista Radical de Tabasco con el modelo corporativista de Benito Mussolini (Martínez, 1984, 
p. 258). Asimismo, resulta inevitable comparar el impulso y la existencia de ligas juveniles progubernamentales como el BJR con el de las ONB italianas.

El proyecto garridista se distinguió de otras administraciones regionales por su radicalismo y por el impulso de la modernización de su entidad. Esta comprendió el mejoramiento de las técnicas agrícolas y la comercialización de la producción local (principalmente la exportación de plátano, cacao y palma de coco a Estados Unidos), y social e ideológicamente la elevación del nivel de vida de la población tabasqueña por medio de un sistema de salud más eficiente (López-Wade, 2001), así como la implementación de las campañas antialcohólica, desfanatizadora y promujer.

Uno de los medios para alcanzar dichos fines fue la formación de niños, jóvenes, obreros y campesinos. Como se señala más adelante, la adopción del sistema educativo racionalista -retomando algunos preceptos de la escuela moderna fundada por Francisco Ferrer Guardia, de la experiencia yucateca y de la Casa del Obrero Mundial- fue implementado como la pedagogía oficial durante la administración garridista, muy a pesar de los designios centralizadores de la Secretaría de Educación Pública.

De este modo, junto con la organización y adhesión forzosa de los trabajadores y estudiantes a las ligas de resistencia del partido oficial de la demarcación (el Partido Socialista Radical de Tabasco), la educación fue el medio por excelencia de adoctrinamiento de la población y de sobrevivencia y aplicación del proyecto político garridista (Kirshner, 1976, p. 17). ${ }^{3}$

\section{LA EDUCACIÓN RACIONALISTA EN TABASCO Y EL INSTITUTO JUÁREZ}

Uno de los objetivos del presente trabajo es observar la influencia del sistema educativo tabasqueño sobre la juventud de la entidad, particularmente en la formación ideológica del BJR. De hecho, es difícil imaginar la existencia y

${ }_{3}^{3}$ De acuerdo con Alan Kirshner (1976), las ligas de resistencia probablemente se habían inspirado en las constituidas en Yucatán, fungiendo como una forma de control por parte del gobierno estatal de los bloques de obreros y campesinos que habían participado en la revolución. En el caso específico de Tabasco, los trabajadores adheridos a las ligas recibían, además de buenos sueldos, concesiones como la repartición de utilidades y el derecho a mantener su trabajo. Los opositores del régimen eran expulsados o no podían sumarse a las ligas, lo cual les impediría conseguir un empleo (pp. 17-20). 
sobrevivencia de los "Camisas Rojas", su radicalismo y beligerancia, sin considerar -como lo hace Martínez Assad-que los alumnos del Instituto Juárez nacieron y crecieron con el régimen de Garrido y, por lo tanto, "no tuvieron que someterse a él” (Martínez, 1984, p. 201).

Partiendo de algunas premisas fundamentales del lingüista Teun A. van Dijk (2005, pp. 21-22), la educación -en este caso racionalista-constituyó un elemento utilizado por los miembros de un grupo para reproducir una ideología específica que regularía tanto las relaciones y prácticas inter e intragrupales como los discursos individuales.

Así, la escuela fungió como un espacio que contribuyó a la interiorización de valores y normas que impulsaba Garrido Canabal como parte de su proyecto regional; dicha situación resalta -como algunos teóricos de la educación lo han señalado- el papel del espacio educativo como aparato reproductor de un sistema de dominación (Giroux, 1983; Gramsci, 1971). Sin embargo, no debe olvidarse que dichos espacios también han fungido como sitios de resistencia y negociación.

Como ya se mencionó, el aislacionismo geográfico y la impermeabilidad ideológica del régimen garridista contribuyeron a que los jóvenes consideraran como verdad absoluta los valores aprendidos en todos los espacios de su vida cotidiana. Cabe mencionar también que algunos elementos presentes en las acciones e idearios de los jóvenes tabasqueños se aplicaron entre los sectores izquierdistas de Europa, en algunos casos con posterioridad.

Por ejemplo, en 1933 la Federación de Juventudes Socialistas (Fjs) en España había apoyado las políticas del gobierno de Manuel Azaña que pugnaban por la laicización del Estado como la confiscación de los bienes de la Iglesia y su control sobre la educación; además de impulsar actividades educativas, en su programa la FJs se manifestaba en contra del capitalismo y por la unidad de campesinos y obreros (Souto, 2013, p. 43).

De este modo, algunas ideas implementadas en Tabasco no fueron exclusivas del garridismo, pero quizá su radicalización se constituyó como la característica distintiva de las juventudes de la entidad.

En este proceso de formación ideológica, la educación racionalista desempeñó un papel fundamental en la radicalización de las juventudes tabasqueñas. Concebida por el pedagogo anarquista español Francisco Ferrer Guardia (1859-1909), la educación racionalista fue implementada por primera vez en México por el Grupo Anarquista Luz en la Casa del Obrero Mundial en la ciudad de México en 1912, posteriormente en Yucatán en 1917 por el 
profesor José de la Luz Mena durante las administraciones de Salvador Alvarado y Felipe Carrillo Puerto. Desde la llegada de Garrido a la gubernatura de Tabasco en 1925, fue adoptada como la pedagogía oficial del régimen e implementada en las escuelas primarias y rurales del estado.

A grandes rasgos, la escuela racionalista se oponía a la educación tradicional al considerar a la experiencia, es decir, la participación del educando, como el recurso didáctico fundamental y no la memorización y el verbalismo (Tostado, 1991, p. 33). Uno de los objetivos de la implementación de la educación racionalista fue el control sociocultural de la población de la demarcación a partir del modelamiento de sus convicciones y de la difusión de la música, la literatura, el folclor, la arqueología y la educación cívica (Giuseppe, 2011, p. 646).

Como su nombre lo indica, la educación racionalista consideraba a la ciencia y a la razón como los únicos medios para alcanzar el conocimiento de la realidad y, contrariamente a la educación positivista, pugnaba por la igualdad social, la supresión de los dogmas, los prejuicios y el fanatismo religioso (Tostado, 1991, p. 33). Así, en 1930 sus objetivos se resumían de la siguiente manera:

Solamente la creación de muchas Escuelas Racionalistas como se ha hecho en el Estado más progresista de la República, Tabasco el niño ansioso de mejoramiento, conocerá y aquilatará la ideología de la civilización moderna revolucionaria explayando su programa de ilustración se dictaría, a base de sentimientos patrióticos; no acumulando sentimientos religiosos, sino ideales libertarios. ${ }^{4}$

De acuerdo con Marcela Tostado (1991, p. 56) desde los inicios de la escuela racionalista se concibió al educando como un agente activo, motor de la transformación de la sociedad donde imperaran la justicia y la humanidad. Según sus postulados, se esperaba formar individuos interesados en su propia educación con capacidad para manifestarse libremente dentro y fuera de las aulas. Además, junto con el impulso de la reintegración, formación y liberación de las mujeres y a diferencia de otros estados en los que predominaba la separación de sexos en los espacios educativos, en Tabasco se establecieron escuelas mixtas (Martínez, 1986, pp. 132-136).

${ }^{4}$ Francisco Herrera, "Se necesitan muchas escuelas racionalistas", Redención, 4 de enero de 1931 . 
La campaña desfanatizadora -quizá el elemento más característico de la educación en el régimen garridista- combatió el dogma religioso no sólo con la adopción del racionalismo, sino físicamente por medio de la remodelación de iglesias como escuelas y la quema de imágenes religiosas, y culturalmente mediante la sustitución de celebraciones religiosas por ferias y festividades laicas. ${ }^{5}$

Aparentemente sin los resultados esperados, Garrido intentó formar maestros especializados en la educación racionalista e impulsar la educación básica obligatoria en todas las escuelas del estado (Martínez, 1984, p. 66; Tostado, 1991, p. 13). Como una parte sustantiva en la formación de la población -además del cooperativismo, con el que se buscó la autonomía del campesinado-, ${ }^{6}$ el nacionalismo fue otro de los elementos fundamentales en la formación educativa de los tabasqueños; según algunos profesores, su implantación contribuiría a la unión intelectual y moral de los jóvenes, a la generación de un sentimiento de respeto por las artes y la cultura nacional, así como a la emancipación económica respecto a Estados Unidos. ${ }^{7}$

Los padres de familia fueron un medio indispensable para el funcionamiento adecuado de las escuelas racionalistas. Algunos planteles organizaban con éxito juntas periódicas con los tutores; en otros casos, pese a los esfuerzos de los maestros por involucrarlos en la formación de sus hijos, las reuniones eran poco fructíferas porque no asistían o porque se oponían a las políticas educativas. ${ }^{8}$

Por su parte, pocos fueron los estudiantes que manifestaron algunas opiniones sobre dicho sistema educativo, lo que podría demostrar su profundo nivel de asimilación entre la mayoría de los jóvenes al normalizarlo como cotidiano e inapelable. En 1931 Ramón Galguera, alumno del Instituto Juárez, declaraba en el periódico La Voz del Estudiante que los esfuerzos gu-

${ }^{5}$ En 1932, por ejemplo, se invitaba a cambiar la cena de navidad por una para conmemorar el año nuevo. Arturo Gamas, "Intensa animación para despedir el año", Redención, 24 de diciembre de 1932 .

${ }^{6}$ El cooperativismo se traducía en la asociación de trabajadores con el fin de "producir y distribuir sus productos mediante el trabajo colectivo" sin necesidad de un intermediario. Las utilidades debían ser distribuidas entre todos los trabajadores (Tostado, 1991, pp. 70-71).

7 Luz María Ch. de Ramírez Garrido, "La campaña nacionalista”, Redención, 29 de septiembre de 1931.

8 Juana Hernández P., "El hogar y la escuela deben unirse en fraternal abrazo", Redención, 2 de marzo de 1931; Adolfo Arreguín, "La educación y la instrucción de los hijos”, Redención, 2 de julio de 1931. 
bernamentales por difundir la educación racionalista entre todos los sectores de la sociedad tabasqueña contribuían a unificar a las distintas clases sociales y a alejar del oscurantismo clerical a los sectores humildes. De acuerdo con Galguera, estas acciones permitirían una victoria más de las ya alcanzadas por la revolución. ${ }^{9}$

Pese a la independencia educativa del régimen garridista frente a los designios de la Secretaría de Educación Pública, la obligatoriedad de la educación militar implementada por esta última en todas las escuelas federales fue aplaudida y justificada por algunos columnistas del periódico oficialista Redención, por considerarla como un aliciente para la formación de la noción de masculinidad, como una forma para ejercitar el patriotismo en los niños que, además, contribuiría a su desarrollo varonil..$^{10}$

Dicha política resulta importante por la trascendencia que tuvieron el entrenamiento militar y la utilización de armas de fuego entre los miembros del BJR y porque el Instituto Juárez fungió como centro de reunión de dicha organización. ${ }^{11}$

\section{EL INSTITUTO JUÁREZ: BASTIÓN DE LOS FUTUROS DIRIGENTES}

Desde su fundación en 1879 el Instituto Juárez fue una institución destinada a la formación educativa, a nivel preparatoria y profesional, de los futuros cuadros dirigentes de la sociedad tabasqueña. Al igual que otras instituciones educativas del país, el Instituto se convirtió en un espacio difusor del positivismo, así pues su programa emulaba al de la Escuela Nacional Preparatoria (ENP) de la ciudad de México y se seguía un currículum en el que se daba

9 Ramón Galguera M., "Educar al pueblo es labor nacionalista", La Voz del Estudiante, 1 de diciembre de 1931.

10 "La enseñanza militar obligatoria”, Redención, 24 de enero de 1931.

${ }^{11}$ En un artículo de Redención retomado por Alan Kirshner (1976, p. 48) el autor afirmaba que el BJR no era una institución militar, aunque sus integrantes eran preparados para su afiliación con los batallones rojos en caso de que los intereses proletarios lo demandaran. No obstante, algunos documentos de archivo denotan que las prácticas militares se convirtieron en una actividad fundamental de la agrupación; la utilización de armas en desfiles militares y en manifestaciones anticlericales evidencian la importancia de dicha actividad. Fondo Tomás Garrido Canabal. Caja 110, exp. 6, f. 51. Archivo General de la Nación (en adelante AGN), México; Fondo Tomás Garrido Canabal. Caja 110, Exp. 13, f. 5. AGN, México. 
prioridad al estudio de las matemáticas y de las ciencias como la física, la química, la biología, la zoología y la astronomía, aunque también se incluían la historia universal, la de México, literatura y lógica, entre otras (Pérez, 2015, pp. 154-155). En consonancia con las transformaciones de la ENP, con el paso de los años las disciplinas humanísticas fueron adquiriendo mayor peso en los programas de estudio.

A finales de la década de 1920 -ya durante el garridismo-, el Instituto abrió sus puertas al recién establecido a nivel federal "ciclo secundario", pero a diferencia de otros planteles en el país fungió como un plantel mixto (acudían hombres y mujeres). Por otra parte, si bien su plan de estudios respetó las materias estipuladas por la SEP, también incluyó algunas otras asignaturas consideradas indispensables para el "desarrollo de las juventudes rojinegras", como agricultura, pedagogía, psicología y ejercicios militares. ${ }^{12}$

Las actividades en el Instituto Juárez incluían desde veladas literarias y musicales organizadas por el Ateneo Nezahualcóyotl -compuesto por escritores, poetas, músicos y maestros tabasqueños- hasta reuniones organizadas por agrupaciones estudiantiles como la Asociación de Estudiantes Libres del Instituto Juárez (en 1910 Sociedad Tabasqueña de Estudiantes), la Federación Estudiantil Tabasqueña (1931) y el BJR.

La proliferación de este tipo de organizaciones fue consecuente con la evolución del activismo estudiantil a finales de la década de 1920 y la de 1930 (Robinet, 2015). En el caso de Tabasco, dicha influencia más las repetidas exhortaciones de funcionarios y profesores para formar parte activa en la lucha por los principios revolucionarios contribuyeron a la aparición de estas organizaciones, aunque con el rasgo distintivo de que permanecieron bajo el control y supervisión de las autoridades gubernamentales.

De hecho, durante la década de 1930, alumnos como Carlos A. Madrazo, Agapito Domínguez y Drusso Garrido fueron líderes de dichas agrupaciones e incluso de otras ramas de las mismas fundadas en la ciudad de México cuando los dos primeros cursaron sus estudios preparatorios y profesionales en dicha capital. ${ }^{13}$

12 Tomás Garrido Canabal, "Informe del C. Gobernador Constitucional del Estado Lic. Tomás Garrido Canabal", Redención, 2 de octubre de 1931; "Año Escolar de 1933”, La Voz del Estudiante, enero de 1933.

${ }^{13}$ Como la Confederación de Estudiantes Socialistas de México (1934), el Bloque de Jóvenes Revolucionarios del Distrito Federal y la Federación Estudiantil de Escuelas Técnicas Industriales y Comerciales (1934). 
Desde dichas asociaciones estudiantiles tabasqueñas -que operaban dentro del Instituto Juárez-, algunos estudiantes llevaron a cabo labores propias del ideario garridista. Por ejemplo, en junio de 1931, Agapito Domínguez -presidente de la Federación Estudiantil Tabasqueña- y otros miembros de la organización proponían la realización "de campañas de mejoramiento cultural de la masa campesina y en los estudiantes de las regiones apartadas" de la entidad. Los alumnos participantes fueron felicitados por las autoridades del Instituto y por los mismos redactores de Redención. ${ }^{14}$

De esa forma, los estudiantes cumplían con algunos objetivos de la llamada escuela social que defendía el director del plantel Arnulfo Giorgana, quien no negaba el carácter elitista del plantel y justificaba su existencia al forjar a una juventud capaz de representar dignamente a su estado (muchos alumnos cursaban sus carreras profesionales en otras entidades del país), de encabezarlo, de alejarse de vicios y fanatismos y de cristalizar los objetivos de la revolución. ${ }^{15}$

\section{JUVENTUD Y REVOLUCIÓN: DISCURSOS Y EXPECTATIVAS}

El establecimiento de una imagen arquetípica sobre la juventud tabasqueña revolucionaria sirvió como parámetro para la implementación regional de políticas y teorías pedagógicas paralelas e independientes de los programas educativos de la SEP, que se pretendía contribuyeran al fortalecimiento del régimen y a la consolidación del proyecto garridista.

Así, el rescate de los discursos sobre la juventud construidos desde arriba -es decir, por parte de autoridades gubernamentales y políticas de la época-contribuyó al conocimiento de las expectativas sobre la juventud durante el régimen garridista y de las funciones sociales y políticas otorgadas a dicho grupo de edad, así como de las razones de la implementación de programas educativos $y$, finalmente, los objetivos que se buscaba alcanzar en un corto plazo a partir de los proyectos regionales.

Por otro lado, el análisis de los discursos construidos desde abajo -es decir, por parte de los jóvenes, todos ellos estudiantes-coadyuva a la compren-

\footnotetext{
14 “Labor cultural de los estudiantes del Instituto “Juárez”, Redención, 16 de junio de 1931.

15 “Otra opinión respecto a la Escuela Social”, Redención, 24 de junio de 1934.
} 
sión del papel que los mismos jóvenes percibían como propio en la sociedad posrevolucionaria tabasqueña, el nivel de asimilación o acomodación de los discursos y políticas gubernamentales y las razones de sus prácticas sociales.

Tomando en cuenta el autoritarismo del régimen garridista es importante rescatar los discursos sobre la juventud procedentes de fuentes oficiales como los periódicos Redención, órgano informativo del gobierno de Garrido Canabal, y La Voz del Estudiante, publicado mensualmente por los estudiantes del prestigioso Instituto Juárez de Tabasco, único centro educativo en el estado que albergaba una escuela secundaria y preparatoria. Las fechas consultadas en ambos casos abarcan de 1931 a 1935, las cuales corresponden el periodo constitutivo y de funcionamiento del BJR de Tabasco.

\section{REDENCIÓN: \\ LA JUVENTUD OBSERVADA DESDE ARRIBA}

El diario Redención apareció por primera vez el 23 de julio de 1924 fungiendo, conjuntamente con $\mathrm{La} \mathrm{Voz}$ del Estudiante, como los únicos periódicos con contenido político en la entidad y medios de difusión de la ideología garridista. Sus contenidos fueron controlados por la Liga Central de Resistencia (LCR) del Partido Socialista Radical Tabasqueño que encabezaba el gobernador en turno. Entre sus colaboradores había funcionarios, maestros, estudiantes preparatorianos y de las escuelas normales del estado y de otras entidades del sureste del país. En algunos artículos se relataban ferias, celebraciones, congresos organizados en la demarcación y la participación de tabasqueños en eventos culturales en los estados colindantes o en la capital del país. Otros más se enfocaban en la difusión de los objetivos del régimen y resaltaban, por ejemplo, las grandes contribuciones de la educación racionalista; la importancia de las campañas desfanatizadora, antialcohólica, nacionalista y promujer; los beneficios del ahorro, del cooperativismo y de la educación y los avances del estado en técnicas agrícolas y de los servicios de salud.

No obstante, sus páginas también sirvieron para denunciar a los opositores políticos del régimen, la falta de compromiso de algunos miembros de las Ligas respecto al pago de cuotas de afiliación y en cuanto al consumo de bebidas alcohólicas (Martínez, 1984, p. 169), así como la adopción de modas extranjeras. 
Las noticias y columnas publicadas en Redención reforzaron los objetivos de las Ligas de Resistencia supeditadas a la LCR y organizadas en todos los municipios del estado. Contribuyeron, por ejemplo, a elevar el nivel intelectual y moral de los trabajadores, a "convulsionar las consciencias retardatarias", a promover entre las clases laborantes el amor por la tierra y el trabajo, así como a combatir el fanatismo religioso y a promover la lucha contra los vicios, preocupación común de la época entre organizaciones religiosas y gubernamentales (Martínez, 1986, p. 169). Algunos articulistas enaltecían la organización de las mujeres en la vida política, laboral y social del estado (Tostado, 1991).

Otros más alentaban la incorporación de los jóvenes en el proyecto garridista, aplaudían la formación del BJR y su participación en el cumplimiento de los designios gubernamentales a partir de la destrucción de imágenes religiosas, de la confiscación de alcohol en los hogares tabasqueños y de las organizaciones estudiantiles izquierdistas como la Confederación de Estudiantes Socialistas del Sureste.

Para los articulistas de Redención, en la juventud recaía la misión de proseguir con la obra redentora de la revolución mexicana, a la que algunos autores como el yucateco Emilio Alcocer traducían como la revolución proletaria. Asimismo, dicho autor afirmaba que la década de los treinta era un momento propicio para abandonar los prejuicios -particularmente los de aquella vieja generación- sobre dicho grupo de edad, es decir los jóvenes, a quienes se los juzgaba por su desapego respecto a los acontecimientos del pasado y por su falta de compromiso con la sociedad y con la patria. Para Alcocer, de mantenerse dicha postura, las viejas generaciones propiciarían la extinción del proyecto revolucionario:

...aunque digan lo contrario grandes personalidades surgidas al calor de la hoguera revolucionaria que la juventud sienta la nostalgia del pasado. En este caso la juventud no se tiene la culpa [sic], sino culpables son, los hombres que enarbolando la bandera revolucionaria más se ocupan en procurar su bienestar personal que en sostener los principios que juran sacar avantes. ${ }^{16}$

Para Alcocer era fundamental la renovación de los hombres por medio de la educación, la transformación de las conciencias, el impulso del pensa-

16 “Emilio Alcocer. La juventud y la revolución”, Redención, 1 de diciembre de 1931. 
miento independiente, del amor a la patria y de su preocupación por el porvenir. En este sentido, el futuro del país y de la revolución radicaba en la preparación de los jóvenes y en la desinteresada participación de los individuos en la vida política nacional. Destacaba el apoyo otorgado por el gobierno tabasqueño para las nuevas generaciones para la formación del BJR y proponía, por lo menos al gobierno de Yucatán, emular dichas acciones.

Alcocer no era el único que rescataba el papel de los jóvenes como motores de la revolución política en el sureste y en el país. En una entidad cuyas autoridades consideraron fundamental el impulso de la educación para el mejoramiento social como Tabasco (Tostado, 1991, p. 164) no resulta extraño que los estudiantes fueran considerados promotores de la modernización del país. La inversión estatal en la infraestructura educativa y el establecimiento de la educación racionalista como el sistema pedagógico oficial de la demarcación debían verse reflejados en la sobrevivencia del proyecto garridista.

Paradójicamente, casi todas las referencias a la juventud estudiosa en Redención aludían a los alumnos del Instituto Juárez y en contadas ocasiones a los de las escuelas normales de la entidad. Esto se explica porque si bien en los discursos se resaltaba la existencia de una clase estudiantil en la que no había estratificación social, la realidad mostraba que pocos jóvenes ingresaban a niveles superiores de educación. ${ }^{17}$

Así pues, los estudiantes del Instituto Juárez fueron preparados como políticos de la entidad, emisarios y propulsores de la ideología garridista y, en casos particulares, como líderes del Partido Nacional Revolucionario (PNR). Incluso fueron muchas las notas en que se hacía referencia a los éxitos y participación de los alumnos del Instituto Juárez tanto en actividades culturales como en conmemoraciones y despedidas para proseguir sus estudios en la capital de país.

Pese a dicha realidad, de acuerdo con el licenciado Miguel Paredes Campos, al constituir un grupo que trascendía las barreras de clase los estudiantes eran el eslabón que uniría a las autoridades gubernamentales con los obreros y campesinos, por lo que componían un sector que contribuiría a la cohesión social de la entidad: "Como clase, como grupo social que significa la adolescencia y la juventud de un País [sic], la grey estudiantil es un derivado social que une los demás grupos, porque en él no hay estratificaciones, ni li-

17 Miguel Paredes Campos, "La juventud estudiosa y el proceso de la nacionalidad mexicana”, Redención, 20 de agosto de 1931. 
mitaciones de un solo klan [sic] social; en ella caben ricos y proletarios en una sola aspiración de la cultura." ${ }^{18}$

Y así caracterizaba a la juventud perteneciente a la era revolucionaria:

No encontraríamos el vocablo para poder decir en una sola palabra, todo lo que significa para el país la clase estudiosa de hoy; pero sí diremos que la juventud de estos últimos veinte años es una juventud bien distinta a la anterior. La de hoy es de lo radical, estriba en un anhelo por el mejoramiento de la clase social trabajadora en el orden moral y económico; posee un sentido nuevo de la justicia, no en una justicia basada en dar a cada uno lo que es suyo, sino en restar dentro de esta injusta distribución de la riqueza el exceso de los ricos a favor de los pobres, en esta una juventud que ha derribado los mitos religiosos y que desea derribar los mitos políticos. ${ }^{19}$

Vale la pena resaltar que, a grandes rasgos, dicho párrafo replica las principales funciones del BJR y de sus filiales en los estados, como el mejoramiento de la juventud estudiosa y trabajadora y el combate de las costumbres malsanas y el fanatismo. ${ }^{20} \mathrm{O}$ bien, de acuerdo con algunos políticos de la región, la promoción de algunas posturas propias de la revolución mexicana como el anticlericalismo, la justicia social para los trabajadores, la distribución de la riqueza y un nuevo orden moral.

El BJR agrupaba a los jóvenes de ambos sexos de 15 a 30 años que supieran leer y escribir, con "convicciones definidas fustigadores de vicios y analfabetismo". Además, el BJR fungiría como una herramienta para apoyar a algunos de los candidatos a la presidencia de la república como Aarón Sáenz, Pascual Ortiz Rubio y Lázaro Cárdenas (Kirshner, 1976, pp. 44-45) y garantizar el apoyo gubernamental a su administración.

El deber de los estudiantes como defensores del nacionalismo se encuentra repetidamente en algunas columnas de Redención e incluso en el propio discurso de los estudiantes. $\mathrm{Al}$ respecto, profesores y funcionarios ta-

${ }^{18}$ Miguel Paredes Campos, "La juventud estudiosa y el proceso de la nacionalidad mexicana”, Redención, 20 de agosto de 1931.

${ }_{19}$ Miguel Paredes Campos, "La juventud estudiosa y el proceso de la nacionalidad mexicana”, Redención, 20 de agosto de 1931.

${ }^{20}$ Bloque de Jóvenes Revolucionarios. Estatutos. 1932 p. 10. Fondo Tomás Garrido Canabal. Caja 21, Libro 56. AGN, México. 
basqueños promovieron el rechazo de las modas internacionales, particularmente las costumbres, la educación y el capitalismo estadunidense. ${ }^{21}$

En ese contexto, una idea preponderante en los discursos sobre juventud fue la función de los estudiantes como salvaguardas y difusores del nacionalismo y del progreso nacional. Si bien se enfatizaba la importancia de que México figurara como un país civilizado, es decir, que se destacara a la par de potencias económicas y culturales y que incluso estrechara lazos con ellas, esto debía suceder con una identidad nacional propia.

Entonces, la misión de los jóvenes era el conocimiento de la historia patria, la exaltación del arte en todos sus aspectos estéticos y su difusión entre todos los sectores sociales. ${ }^{22}$ Cabe destacar que, pese a que el nacionalismo pregonado durante el garridismo impulsaba el rescate y difusión de la música, el folclor y la arqueología regional, el gobierno tabasqueño alentaba a las comunidades indígenas a que se abrieran a la modernización social y técnica, es decir, a desterrar las ideas y celebraciones religiosas y a alejarse del consumo del alcohol, así como a adoptar y aprender técnicas que permitirían una mejor y mayor producción agrícola (Giuseppe, 2011, pp. 643-647).

\section{LA VOZ DEL ESTUDIANTE: LA JUVENTUD OBSERVADA POR SÍ MISMA}

La Voz del Estudiante fue el periódico oficial de los alumnos del Instituto Juárez fundado en 1930 y de distribución gratuita. Aunque inicialmente era de carácter mensual, por cuestiones políticas y de financiamiento apareció de forma irregular hasta 1939. Durante los años analizados su publicación estuvo a cargo de algunos alumnos distinguidos del Instituto como Carlos A. Madrazo, líder del BJR y futuro gobernador de Tabasco y presidente nacional del Partido Revolucionario Institucional (PRI); J. Alfredo Rajme y Antonio Ocampo R., integrantes del BJR, así como por Ezequiel Jesús de Dios, futuro editor de varios periódicos tabasqueños.

${ }^{21}$ José María Dávila, "La educación en el extranjero como succión a nuestra riqueza”, Redención, 21 de junio de 1931; Consuelo Marín, "La amenaza rubia”, Redención, 7 de julio de 1931.

${ }^{22}$ Miguel Paredes Campos, "La juventud estudiosa y el proceso de la nacionalidad mexicana”, Redención, 20 de agosto de 1931. 
De 1931 a 1933 fungieron como jefes de redacción Drusso Garrido Llovera, primogénito del entonces gobernador, así como Eduardo Alday, años más tarde rector de la Universidad Juárez Autónoma de Tabasco, y Pedro Giorgana, hijo del director del Instituto Juárez, Arnulfo Giorgana. Como articulistas participaron estudiantes y exalumnos del plantel, líderes estudiantiles de izquierda de otros estados, profesores y, en pocas ocasiones, políticos de la administración tabasqueña.

En La Voz del Estudiante se abordaban diversas temáticas, desde poemas patrióticos hasta declaraciones de amor en las que llegó a darse el caso de que chicos y chicas confesaran su afecto por algunos de sus compañeros (o incluso abiertamente por las novias de sus amigos)..$^{23}$ Asimismo, abundaban noticias sobre las actividades de la institución, exhortaciones respecto al papel de los jóvenes, exaltaciones de la política garridista, ataques a los sectores opositores (la Iglesia católica), artículos acerca de enfermedades de alto impacto en la región, fotografías de los miembros distinguidos de la comunidad estudiantil, lecciones de biología y agricultura, ensayos sobre los problemas y la política regional, nacional e internacional (predominantemente latinoamericana) e invitaciones y crónicas de eventos celebrados por alumnos del Instituto. ${ }^{24}$

En algunas columnas es perceptible el desengaño de los jóvenes ante las acciones de los viejos revolucionarios. Así pues, se consideraban los únicos que podían concretar los postulados de la revolución. De hecho, algunos miembros y líderes del BjR llamaban a esta supuesta fase una "nueva revolución" al considerar que habían quedado olvidados algunos postulados revolucionarios como la reivindicación del campesinado, el reparto agrario y la distribución equitativa de la riqueza. ${ }^{25}$ Ellos mismos se concebían como los únicos garantes para el enderezamiento del rumbo del país, todo ello mediante la acción colectiva y el impulso del socialismo en su versión garridista. ${ }^{26}$

${ }^{23}$ Herlindo Soberano I., "Si tú supieras", Redención, 30 de noviembre de 1932.

${ }^{24}$ Por mencionar algunos: María Luisa Ch. de Ramírez Garrido, "Los nuevos rumbos del pensamiento de Tabasco", La Voz del Estudiante, 1 de diciembre de 1931; Gabriel I. Ezeta, "Ibero-América: su problema capital", La Voz del Estudiante, 1 de enero de 1931; "Por el idioma nacional”, La Voz del Estudiante, 1 de agosto de 1932; Carlos Eduardo Vargas, "¿Qué es el imperialismo dentro del concepto económico moderno?”, La Voz del Estudiante, 1 de enero de 1933.

${ }^{25}$ Francisco Carmona, ¿Qué es ser revolucionario? 1935. Fondo Tomás Garrido Canabal. Caja 110, exp. 21, f. 8. AGN, México.

${ }^{26}$ Antonio Ocampo, Renglones [ilegible]. Fondo Tomás Garrido Canabal. Caja 110, exp. 21, f. 14. AGN, México. 
En 1933, Rafael Martínez Amezcua, integrante del BJR, invitaba a los jóvenes tabasqueños a unirse a la lucha revolucionaria con las siguientes palabras:

Nuestro problema será resuelto por el contingente hasta ahora relegado en la inopia; nuestro problema económico y social será resuelto por los ejércitos de una nueva REVOLUCIÓN DEMOCRÁTICA; por la reciente y viril juventud renovadora, por las huestes juveniles de la VANGUARDIA, por los eternos enemigos de la conservación; por los atletas del músculo y Del Cerebro. [...] tendrán los soldados de esta leal revolución, el sincero y merecido SALUDO DE SU PATRIA, y también tendrán, la satisfacción del GRITO DE LIBERTAD que repercutirá en el alma bien modelada de las GENERACIONES VENIDERAs. ${ }^{27}$

Los escritos de los estudiantes denotaban acusados esfuerzos por la búsqueda de autonomía y participación política en el rumbo del país y en la resolución de los problemas nacionales. ${ }^{28}$ Incluso, años más tarde, del separatismo corporativo que emprendió el gobierno nacional -particularmente durante la administración de Lázaro Cárdenas (Aziz, 1989, p. 54)-llamaban a la acción conjunta de jóvenes obreros, campesinos y estudiantes para alcanzar dichas transformaciones. ${ }^{29}$

No obstante, algunos documentos atestiguan que dicha autonomía fue relativa, pues pervivían medidas disciplinarias para los alumnos rebeldes del Instituto Juárez y una vigilancia y control constantes, por parte de Garrido, de las actividades del BJR y de la Confederación de Estudiantes Socialistas de México que encabezaban líderes juveniles del Bloque. ${ }^{30}$

La lucha estudiantil no sólo se circunscribió a reforzar el cumplimiento de los postulados revolucionarios y a implementar la política anticlerical y la campaña contra los vicios de Garrido, sino que también se enfocó contra la vorágine del capitalismo - principalmente estadunidense- $y$, aunque

${ }^{27}$ Rafael Martínez Amezcua, "La juventud vanguardista del estado de Tabasco", La Voz del Estudiante, enero de 1933.

28 "Bandera de Principios de la Juventud Mexicana. XI Congreso Nacional de Estudiantes”, La Voz del Estudiante, 31 de agosto de 1932.

${ }^{29}$ Santiago Aguirre Zertuche, “¡A la juventud!”, La Voz del Estudiante, 21 de marzo de 1932.

${ }^{30}$ Fondo Tomás Garrido Canabal. Caja 54, exp. 8, f. 18, 1934. AGN, México; Fondo Tomás Garrido Canabal. Caja 54, exp. 8, f. 116, 1934. AGN, México. 
en menor medida, en pro de la liberación de América Latina de la opresión imperialista.

Es doloroso, pero necesario, hablar y hablar claro, acerca de los problemas que afectan a nuestra América; sin embargo este dolor es compensado con la satisfacción que me causa la idea de que me voy a dirigir a la Juventud Tabasqueña que, como la de mi Estado es fuerte y vigorosa, sabe poner el dedo en la llaga y con voz preponderante hace saber a nuestra Patria y sus hermanas las Repúblicas del Sur, que es indispensable estar alertas para poder defender en cualquier forma nuestra soberanía e integridad nacionales de las acechanzas traidoras y falaces de los sicarios yanquis, manequíes [sic] del capitalismo norteamericano judío. ${ }^{31}$

Aunque procedente del Estado de México, Gabriel L. Ezeta -fundador y director de la revista Génesis, perteneciente a la Liga de Estudiantes de dicha entidad-mediante una columna enviada a La Voz del Estudiante proponía a los jóvenes tabasqueños diferentes formas de resistencia frente a la denominada "amenaza estadunidense". Una de ellas era la obligación de difundir la "cultura latina", que para el caso mexicano se constituía en la defensa de la música nacional frente al jazz y otros ritmos "importados de los más obscuros y salvajes rincones africanos", así como de la arquitectura colonial ante los grandes rascacielos.

También era fundamental la cooperación de los jóvenes con los gobiernos revolucionarios en el establecimiento de la industria nacional que permitiría la salvación material del país. ${ }^{32}$ Pese a la delegación de ciertas responsabilidades al Estado, Gabriel Ezeta insinuaba la buena reputación y la posición intermediaria o quizá preponderancia de los estudiantes respecto a la sociedad civil: "Debe también saber el pueblo, que en este caso, la Juventud tiene la firme convicción de que el gobierno revolucionario y hará [sic] enérgica reclamación al Estadounidense [por los abusos que ha dado lugar la Doctrina Monroe, entre ella asesinatos de paisanos], demostrando así que

${ }^{31}$ Gabriel L. Ezeta, "Ibero-América: su problema capital”, La Voz del Estudiante, 1 de enero de 1932. Cursivas mías.

${ }^{32}$ Gabriel L. Ezeta, "Ibero-América: su problema capital”, La Voz del Estudiante, 1 de enero de 1932. Esta misma retórica y beligerancia contra la cultura estadunidense se puede encontrar en un artículo de la revista Génesis rescatado en el periódico tabasqueño: Teodormiro Torres G., "El imperialismo yanqui: problema capital", La Voz del Estudiante. 31 de agosto de 1932. 
tantos años de luchas no han sido estériles para conseguir que sea México una nación libre y respetada." 33

Otros líderes estudiantiles -como los tabasqueños Carlos A. Madrazo y Antonio Ocampo R., y el sinaloense Jesús Lazcano- también alzaron la voz para exhortar a sus jóvenes lectores sobre el papel primordial que recaía en ellos para la defensa de la cultura y economía mexicana frente a Estados Unidos. $^{34}$

Vale la pena destacar que la postura del régimen garridista era un tanto aislacionista, e incluso se oponía, por ejemplo, al panamericanismo, por considerarlo una herramienta estadunidense para reforzar el dominio sobre los países latinoamericanos. Aunque no es el tema central de esta investigación, cabe mencionar que desde finales de la década de 1920 los movimientos estudiantiles mexicanos no fueron ajenos al papel liberador que su grupo social en conjunto con las juventudes latinoamericanas, tenía respecto al imperialismo y la defensa cultural, política y económica de sus países.

Por ejemplo, entre diciembre de 1930 y enero de 1931 se celebró en México el Primer Congreso de Estudiantes Iberoamericanos organizado por la Confederación Nacional de Estudiantes (Robinet, 2015, pp. 532-545); por esas mismas fechas también se llevó a cabo la Primera Convención Iberoamericana de Estudiantes Católicos, que daría vida a la Confederación Nacional de Estudiantes Católicos (CNEC), quienes eran considerados por el BJR "juguetes inconscientes de los conservadores y del arzobispo de México" (Aspe, 2008, pp. 82-83; Hinojosa, 1935, p. 77).

\section{CONCLUSIONES}

Por los quince años de duración del régimen garridista en Tabasco, el aislamiento geográfico de la región y el control sobre las actividades de sus habitantes, es evidente que la presencia de los discursos antirreligiosos, políticos (de corte socialista), las campañas antialcohólica, la de promujer y la educación racionalista se integraron normativamente a las prácticas cotidianas de 1932

${ }^{33}$ Gabriel L. Ezeta, "Ibero-América: su problema capital", La Voz del Estudiante, 1 de enero

${ }^{34}$ Carlos A. Madrazo, "Juventud y capitalismo", La Voz del Estudiante, 1 de enero de 1932; Antonio Ocampo, "Sentires libertarios", La Voz del Estudiante, 31 de agosto de 1932; Jesús Lazcano, "Editorial", La Voz del Estudiante, 30 de septiembre de 1932. 
-en algunos casos con mayor éxito que en otros- como "fórmulas" exitosas, legítimas y únicas frente a los proyectos, prácticas e ideologías de grupos de oposición de la misma entidad federativa (como grupos de católicos u otros partidos políticos) o de otros estados.

En los discursos sobre la juventud de sectores hegemónicos adultos (políticos y maestros) y de estudiantes del Instituto Juárez -muchos de ellos integrantes del BJR-es posible apreciar la similitud de expectativas entre uno y otro grupo en cuanto al papel de los jóvenes en la sociedad tabasqueña. Ambas partes refieren la importancia de un cambio de actitud intergeneracional y la necesidad de iniciar una nueva relación entre ambos grupos desterrando los viejos estereotipos que señalaban a los jóvenes como individuos apartidistas, egoístas y poco comprometidos con la vida política y con el mejoramiento social de su comunidad.

Si bien en las columnas de Redención no existe en realidad alusión a la necesidad de la supervisión adulta, en los documentos de archivo y en la composición de los dirigentes del BJR (todos con vínculos muy estrechos con Garrido: parientes o familiares de funcionarios cercanos al gobernador) se pueden encontrar indicios constantes del control, vigilancia e incluso instrucción sobre las actividades a desempeñar.

No obstante, gran parte de los escritos de los jóvenes en La Voz del Estudiante exaltaban la independencia, la iniciativa de la organización y la participación política de su grupo etario, e incluso llegaban a anunciar el inicio de una nueva etapa de la revolución en la que los jóvenes sí darían cumplimiento a las demandas sociales (justicia social) olvidadas por los "antiguos" líderes revolucionarios. De hecho, un reflejo del grado de asimilación de las funciones de la juventud pregonadas por el garridismo en los periódicos mencionados se materializó en las acciones llevadas por la BJR como las cruzadas antialcohólicas, en la quema de artículos religiosos, en la denuncia de opositores políticos y en los sucesos de Coyoacán, acontecimientos bien documentados por Kirshner (1976) y Martínez Assad (1984).

Uno de mis principales objetivos ha sido un primer acercamiento para conocer el papel que desempeñaron la educación formal e informal garridista en la formación de los jóvenes de Tabasco, así como en el establecimiento y la sobrevivencia del BJR y, desde luego, en la adscripción voluntaria de hombres y mujeres a sus filas. 
Aunque resulta incuestionable la capacidad de agencia de los sujetos, evidente en algunos opositores políticos como el joven Andrés Iduarte y la Unión de Estudiantes Tabasqueños (Kolar, 2016) -tema que merece una investigación más profunda-, también es innegable el impacto de la difusión de la ideología del régimen garridista (por medio del currículum escolar, las prácticas en los planteles y los medios de comunicación) en la formación de modelos mentales que dieron sentido a una realidad determinada y consolidaron el sentimiento de cohesión social al tener ciertos objetivos en común.

En otras palabras, las ideas y costumbres que promovían la escuela racionalista tabasqueña y los periódicos mencionados influyeron en la forma en que niños y "adolescentes" nutrieron su marco de referencias; asimismo, contribuyeron a que la realidad del tabasco garridista fuera su punto de partida y referente (idealizado) respecto al resto de las realidades sociales y políticas de otros grupos sociales (religiosos y políticos).

Quizá esta situación coadyuvó a la actitud contestataria que caracterizó a los miembros del BJR, pues el socialismo que pregonaba Garrido repetidamente fue enarbolado como la única manera de alcanzar los objetivos de la revolución mexicana.

Así pues, la injerencia del régimen tabasqueño en todas las actividades cotidianas de la entidad llevó a la normalización de las premisas y proyectos gubernamentales en grandes sectores poblacionales. De hecho, el alejamiento de Garrido de la vida política en Tabasco y del país, tras su destitución de la Secretaría de Agricultura en 1935 y su exilio en Costa Rica, propició la desintegración del BJR en la ciudad de México. ${ }^{35}$

Los resultados de la investigación refuerzan algunos presupuestos sobre el funcionamiento y la constitución histórica de los Estados-nación proporcionados por la ciencia política, la antropología y la historia. Particularmente en este artículo me he basado en las aproximaciones teóricas propuestas por el politólogo Jeffrey W. Rubin (2003), quien ubica la participación en México de diversas fuerzas sociales y en distintos niveles (regional y nacional) en la constitución de la imagen de un Estado fuerte.

En el caso tabasqueño resulta evidente que la construcción hegemónica del Estado no fue unidireccional (es decir, Estado-resto de la población),

${ }^{35}$ A ello se debe agregar que, aunque estaba encabezado por Agapito Domínguez y Carlos. A. Madrazo el BjR de la ciudad de México fue constituido por estudiantes y jóvenes obreros capitalinos, es decir, con una formación educativa distinta a la tabasqueña. 
sino que fue el común de la población (en este caso los jóvenes) el que contribuyó al fortalecimiento de la imagen hegemónica del poder gubernamental estatal y regional y a la vitalidad de los proyectos político-sociales.

De este modo, se puede afirmar que el régimen garridista observó la educación de los jóvenes como un medio de consolidación de su fuerza hegemónica y de sobrevivencia de su proyecto político por varias generaciones.

En suma, la normalización de las prácticas cotidianas de la población tabasqueña bajo el control y codificación del Estado -a partir de la educación y de los medios de comunicación- se convirtió en el referente que se pretendía que fuera reproducido años más tarde por los jóvenes tabasqueños, incluso a escala nacional. La causa la abrazaría el BJR.

\section{LISTA DE REFERENCIAS}

Apple, M.W. (2008). Ideología y currículo. Madrid: Akal.

Aspe Armella, M. L. (2008). La formación social y política de los católicos mexicanos: la Acción Católica Mexicana y la Unión Nacional de Estudiantes Católicos: 1929-1938. México: Universidad Iberoamericana/Instituto Mexicano de Doctrina Social Cristiana.

Aziz Nassif, A. (1989). El Estado mexicano y la cтM. México: ciesas (Ediciones de la Casa Chata).

Canudas, E. (1989). Trópico rojo: historia politica y social de Tabasco: los años garridistas 1919/1934 (vol. 1). Villahermosa: Gobierno del Estado de Tabasco/ICT Ediciones.

Comacchio, C. (2006). The dominion of youth. Adolescence and the making of modern Canada, 1920 to 1950. Waterloo: Wilfrid Laurier University Press.

Cox, P. W. L. (1935). Opera Nazionale Balilla: An aspect of Italian education. Junior-Senior High School Clearing House, IX(5), 267-270. Recuperado de http://www. jstor.org/stable/30176386

Dijk, T. A. van (2005). Política, ideología y discurso. Quórum Académico, II(2), 15-47.

Fincardi, M. (2007). Italia: primer caso de disciplinamiento juvenil de masas. Hispania. Revista Española de Historia, LXVII(225), 43-72. DOI: https://doi.org/10.3989/ hispania.2007.v67.i225.35

Gillis, J. R. (1974). Youth and history. Tradition and change in European age relations 1770-present. Nueva York: Academic Press. 
Giroux, H. (1983). Theories of reproduction and resistance in the new sociology of education: A critical analysis. Harvard Educational Review, LIII(3), 257-293. DOI: http://dx.doi.org/10.17763/haer.53.3.a67x4u33g7682734

Giuseppe, M. de (2011). El Tabasco racionalista: entre laboratorio social y experimentación cultural (1922-1934). Historia Mexicana, LXI(2), 643-706. Recuperado de https://historiamexicana.colmex.mx/index.php/RHM/article/view/268/245

Gramsci, A. (1971). Selections from the prison notebooks. Nueva York: International Publishers.

Harvey, E. (1993). Youth and the welfare state in Weimar Germany. Oxford: Clarendon Press.

Hinojosa, R. (1935). El Tabasco que yo he visto. México: Talleres Gráficos de la Oficina de Publicaciones y Propaganda de la Secretaría de Agricultura y Fomento.

Kett, J. F. (1977). Rites of passage. Adolescence in America 1790 to the present. Nueva York: Basic Books.

Kirshner, A. M. (1976). Tomás Garrido Canabal y el movimiento de los Camisas Rojas. México: SEP.

Kolar, F. (2016). Memorias en acción. Un niño en la revolución mexicana de Andrés Iduarte Foucher. Historia Mexicana, LXVI(1), 299-357. DoI: http://dx.doi. org/10.24201/hm.v66i1.3248

López-Wade, A. (2001). Síntesis histórica de los servicios de salud en el Estado de Tabasco (1a. parte). Salud en Tabasco, vi(1), 377.

Martínez Assad, C. (1984). El laboratorio de la revolución. El Tabasco garridista. México: Siglo Veintiuno Editores.

Martínez Assad, C. (1986). Los lunes rojos. La educación racionalista en México. México: Ediciones El Caballito.

Martínez Assad, C. (coord.) (1988). Estadistas, caciques y caudillos. México: Instituto de Investigaciones Sociales-UNAM.

Pérez Castro, J. (2015). Avatares y desafíos del Instituto Juárez de Tabasco. Secuencia, 91, 149-170. DoI: https://doi.org/10.18234/secuencia.v0i91.1252

Robinet, R. (2015). L'esprit et la race. Le mouvement étudiant face à la Révolution mexicaine (1910-1945). (Tesis de doctorado inédita). Instituto de Estudios Políticos, París.

Rubin, J. W. (2003). Descentralizando el régimen. Cultura y política regional en México. Relaciones. Estudios de Historia y Sociedad, xxIV(96), 126-180.

Souto Kustrín, S. (2007). Juventud, teoría e historia. La formación de un sujeto social y de un objeto de análisis. HAOL, 13, 171-192. Recuperado de http://historia-actual.org/Publicaciones/index.php/haol/article/view/208/196 
Souto Kustrín, S. (2013). Paso a la juventud. Movilización democrática, estalinismo y revolución en la República Española. Valencia: Universidad de Valencia.

Torres Vera, M. T. (2001). Mujeres y utopía. Tabasco garridista. Villahermosa: Universidad Juárez Autónoma de Tabasco.

Tostado Gutiérrez, M. (1991). El intento de liberar a un pueblo. Educación y magisterio tabasqueño con Garrido Canabal, 1924-1935. México: ENAH.

Urías Horcasitas, B. (2007). Historias secretas del racismo en México (1920-1950). México: Tusquets.

Vries, P. de (2002). Vanishing mediators: enjoyment as a political factor in western Mexico. American Ethnologist, $\operatorname{xxIx(4),~901-927.~}$

\section{OTRAS FUENTES}

\section{Archivo}

AGN Archivo General de la Nación, México.

\section{Hemerografía}

Redención.

La Voz del Estudiante.

\section{Bibliografía}

Caron, J. C. (1996). La segunda enseñanza en Francia y en Europa, desde finales del siglo XVIII hasta finales del siglo xIX: colegios religiosos e institutos. En G. Levy y J. C. Schmitt (coords.), Historia de los jóvenes. II. La edad contemporánea (pp. 171237). Barcelona: Taurus.

Malvano, L. (1996). El mito de la juventud a través de la imagen: el fascismo italiano.

En G. Levy y J. C. Schmitt (coords.), Historia de los jóvenes. II. La edad contemporánea (pp. 311-345). Barcelona: Taurus.

Michaud, E. (1996). "Soldados de una idea": Los jóvenes bajo el Tercer Reich. En G. Levy y J. C. Schmitt (coords.), Historia de los jóvenes. II. La edad contemporánea (pp. 347-379). Barcelona: Taurus. 